\title{
O elemento referencial na construção de significados do gênero fábulas
}

\author{
Forge Bidarra* \\ Leidiani da Silva Reis ${ }^{\star \star}$
}

\section{Resumo}

Em vista da dificuldade que os alunos sentem ao interpretar um texto, o presente artigo tem por objetivo refletir acerca do processo interpretativo no ensino de língua portuguesa. Mais especificamente, discute-se sobre o valor que elementos linguísticos exercem no instante da interpretação textual do gênero fábula. Dentre os vários recursos linguísticos existentes, este trabalho aborda elementos que colaboram na construção dos significados e na tessitura do texto, focalizando, então, o processo de referenciação. A fim de promover, considerando os limites e as possibilidades desta investigação, uma compreensão mais precisa do corpus, dentre os elementos referenciais possíveis na língua portuguesa, opta-se por focalizar as retomadas não correferenciais, tendo em vista serem concebidas como uma forma de manifestação do produtor do texto (KOCH, 2005). Parte-se da hipótese de que a abordagem desse recurso linguístico no ensino de língua portuguesa pode auxiliar o aluno na interpretação textual, tendo em vista o seu papel no processo de extração de informações relevantes do texto. Para efeito de sondagem, toma- -se como corpus de análise respostas interpretativas produzidas, a partir de fábulas de La Fontaine, por alunos do $6^{\circ}$ ano de uma escola pública de Cascavel, PR. Constata-se que, ao usar tais anáforas em suas respostas, os alunos deixam transparecer suas escolhas com a finalidade de destacar traços ou características do referente e, assim, avaliá-lo segundo suas crenças e seus pontos de vista. Nessa direção, observa-se que os alunos realizaram estratégias de (re)construção do referente, demonstrando compreensão dos textos lidos.

Palavras-chave: Anáfora não correferencial. Gênero fábula. Interpretação textual. Interconexão linguística e literária.

* Doutor em Linguística pela Unicamp. Professor da Graduação e da Pós-Graduação da Universidade Estadual do Oeste do Paraná (Unioeste).

** Mestra em Letras pela Unioeste. Professora da Graduação e da Pós-Graduação da Associação Juinense de Ensino Superior do Vale do Juruena (Ajes). Coordenadora do Pibid/Letras da Ajes.

Data de submissão: fev. 2013 - Data de aceite: abr. 2013 http://dx.doi.org/10.5335/rdes.v9i1.3545 


\section{Introdução}

Muitas pesquisas destacam que a interpretação e a produção de texto figuram entre as grandes dificuldades enfrentadas pelos alunos do ensino fundamental. Por mais que muitos estudiosos dediquem-se à abordagem de tais questões, há necessidade de constante reflexão nesse sentido, buscando alcançar avanços e melhorias, pois, conforme destaca Marcuschi, a interpretação "não é uma habilidade inata, transmitida geneticamente pela espécie humana" (1996, p. 64), exigindo treino e habilidade constante. Diante disso, nosso trabalho busca refletir sobre a interpretação textual e, ao mesmo tempo, focalizar elementos linguísticos que auxiliam na construção dos sentidos do texto, atuando na tessitura deste por meio do processo de referenciação.

Mais do que estabelecer simples retomadas de elementos linguísticos, a referenciação é responsável por categorizar e recategorizar objetos de discurso, materializando atitudes tomadas pelo produtor para a construção de determinado(s) sentido(s) e imprimindo pistas linguísticas que guiam o leitor na interpretação do texto. Nessa perspectiva, abordamos a referenciação com base na concepção sociocognitiva-interacional, que toma tal processo como uma atividade discursiva (KOCH, 2005).

Uma vez que a pesquisa aqui proposta não permite trabalhar com todos os possíveis elementos referenciais, optamos por focalizar as retomadas não correferenciais - sem a manutenção do núcleo -, tendo em vista o fato de serem concebidas como uma forma de manifestação do produtor do texto $(\mathrm{KOCH}$, 2005). Isso porque utilizar uma anáfora não correferencial para recategorizar um referente implica sempre uma escolha lexical em detrimento de tantas outras possibilidades existentes na língua, e essa escolha pode revelar opiniões, intenções e atitudes do produtor do texto.

Assim sendo, a hipótese principal deste trabalho é a de que a anáfora não correferencial é uma estratégia linguística que pode auxiliar o aluno na interpretação textual, uma vez que é responsável por imprimir sentidos aos enunciados na medida em que revela intenções, valores e posições que o produtor do texto quer expressar. A par dessa hipótese central, levamos em conta o fato, de conhecimento público, de que alunos, via de regra, saem das séries iniciais do ensino fundamental sem pelo menos conseguir decodificar textos. Essa situação conduziu a que optássemos por coletar dados para verificar a pertinência das anáforas não correferenciais em respostas interpretativas produzidas por alunos do $6^{\circ}$ ano. Assim, buscamos refletir sobre o assunto em tela e propor estratégia que contribua para sanar dificuldades relativas à interpretação de texto. Acreditamos que, se trabalhada desde cedo, a abordagem proposta pode contribuir para chegarmos a melhores resultados no que tange à interpretação 
textual dos estudantes, diretamente relacionados às habilidades de leitura e produção textual.

Para instigar a produção dos dados coletados, recorremos à esfera literária, especificamente à fábula, por tratar-se de um gênero já conhecido pelos alunos do $6^{\circ}$ ano. Apesar de aparentemente simples, as fábulas são conduzidas por estratégias linguísticas responsáveis por dotar animais ou objetos de características humanas com o intuito de transmitir uma conduta de vida, o que resulta em textos altamente argumentativos (COELHO, 1984). Assim, buscamos refletir sobre a interface existente entre os estudos linguísticos e literários, base do nosso trabalho.

Adotando como corpus respostas interpretativas dos alunos relacionadas às perguntas sobre as fábulas "A raposa e as uvas" e "O lobo e o cordeiro", verificamos a interpretação que os alunos realizaram a respeito da primeira fábula, dada antes da apresentação da estratégia proposta, e, posteriormente, a respeito do segundo texto, apresentado depois do estudo das anáforas não correferenciais. Desse modo, portanto, o trabalho que empreendemos apresenta-se como uma pesquisa qualitativa, tendo em vista a descrição, compreensão e interpretação dos dados alcançados por meio da investigação sugerida.

\section{Concepções de linguagem e de texto norteadoras do trabalho}

Ancora este trabalho a concepção sociointeracionista de linguagem, na qual os sujeitos são "atores/construtores sociais, sujeitos ativos que - dialogicamente - se constroem e são construídos no texto, considerado o próprio lugar da interação e da constituição dos interlocutores" (KOCH; ELIAS, 2006, p. 10-11).

A perspectiva interacionista de linguagem centra a atenção na relação que se estabelece entre o locutor e o interlocutor, levando em conta as condições de produção do discurso. Segundo Koch, nessa perspectiva,

[...] a linguagem é vista como um modo de ação social. É o elemento de mediação necessária entre o homem e a sua realidade, neste sentido, é lugar de conflito, de confronto dialógico em que a significação se apresenta em toda a sua complexidade. Estudar a linguagem é abarcá-la nessa complexidade, é apreender o seu funcionamento que envolve não só mecanismos linguísticos, mas também extralinguísticos (KOCH, 2001, p. 09).

Assim, a linguagem é forma de ação entre sujeitos históricos e socialmente situados que se constituem e constituem uns aos outros em suas relações dialógicas. Mais do que servir de meio para a transmissão de informações de um emissor a um receptor, ela se configura como "[...] forma ou processo de interação [...], usar a língua não é tão somente traduzir e interiorizar um pensamento ou transmitir informações a outrem, mas 
sim realizar ações, agir, atuar, sobre o interlocutor (ouvinte/falante). A linguagem é pois um lugar de interação humana" (TRAVAGLIA, 2000, p. 23).

Conforme essa concepção, a leitura é um ato social, uma forma de interação movida por precisões e objetivos socialmente definidos, ou seja, é "uma atividade interativa altamente complexa de produção de sentidos" (KOCH; ELIAS, 2006, p. 11). Este trabalho assume a concepção de leitura que parte da perspectiva interacionista de linguagem, como descrito acima, o que implica dizer que todo "processo de aquisição e uso da linguagem relaciona o cognitivo com o social" (MACHADO, 2002, p. 33) e que a língua é ação entre os homens (KOCH, 2001).

Partindo da perspectiva interacionista, a leitura, neste trabalho, é vista como uma atividade a ser ensinada na escola não como mero pretexto para outras atividades e outros tipos de aprendizagem (KLEIMAN, 2004), e sim como uma "atividade em que ressignificamos a palavra, apoiados na nossa experiência prévia, focalizando significados de palavras específicas ou para inferir seu significado, ou para apreciar um uso particular, diferente" (KLEIMAN, 2004, p. 20).

Diante dessa forma de ver a linguagem, o trabalho proposto parte da concepção de texto como "toda ocorrência linguística falada ou escrita, de qualquer extensão, dotada de uma unidade sociocomunicativa, semântica e formal" (COSTA VAL, 1999, p. 3). Sendo assim, se há comunicação e sentido, há texto. Este "[...] se constitui enquanto tal no momento em que os parceiros de uma atividade comunicativa global, diante de uma manifestação linguística, pela atuação conjunta de uma complexa rede de fatores de ordem situacional, cognitiva, sociocultural e interacional, são capazes de construir, para ela, determinado sentido" (KOCH, 2008, p. 30).

Desse modo, não há um sentido único para o texto; há, sim, leituras mais ou menos adequadas, a depender dos objetivos e das intenções do leitor (KLEIMAN, 2004) e do produtor do texto. Em outras palavras, o texto não vale por si só; ele se constitui na interação, o que depende tanto do autor quanto do leitor. Assim sendo, a produção textual é concebida por Koch como:

uma atividade verbal, a serviço de fins sociais e, portanto, inserida em contextos mais complexos de atividades; trata-se de uma atividade consciente, criativa, que compreende o desenvolvimento de estratégias concretas de ação e a escolha de meios adequados à realização de objetivos; isto é, trata-se de uma atividade intencional que $o$ falante, de conformidade com as condições sob as quais o texto é produzido, empreende, tentando dar a entender seus propósitos aos destinatários através da manifestação verbal; é uma atividade interacional, visto que os interactantes, de maneiras diversas, se acham envolvidos na atividades de produção textual (2008, p. 26).

Assim, olhamos para o texto como o resultado de um conjunto de operações realizadas por um sujeito que, numa situação discursiva, busca atingir certos objetivos. Em outras palavras, compre- 
endemos o texto como produto de ação que se volta para um processo de interação, em que alguns indícios discursivos permitem avaliação das condições de produção e dos diferentes movimentos argumentativos que sustentam determinada conclusão. Em outras palavras, "tanto o texto oral quanto o texto escrito são produtos de uma intencionalidade, isto é, escritos por alguém, com alguma intenção de chegar aos outros" (KLEIMAN, 2004, p. 23). O sentido do texto é, então, de acordo com Koch e Elias (2006), construído na interação entre este e os sujeitos, não sendo preexistente a essa interação.

Depois de delimitarmos a concepção de linguagem e, consequentemente, de texto e leitura adotada neste trabalho, buscamos, no próximo tópico, compreender o processo de construção e (re) construção dos objetos do discurso e, na sequência, o papel da anáfora não correferencial no processo interpretativo, uma vez que esta é foco da análise realizada.

\section{Construção e reconstrução de objetos de discurso: a anáfora não correferencial em evidência}

A referenciação, segundo as reflexões de Koch (1998, 2004, 2005, 2006), Marcuschi (2003), Mondada e Dubois (2003), dentre outros autores, configura-se não simplesmente como um recurso de retomada de entidades do mundo; em outras palavras, não diz respeito a simples rótulos usados para designar as coisas do mundo (KOCH; MARCUSCHI, 1998). Muito além disso, retrata uma forma de construção e reconstrução de objetos de discurso. Depois de lançado (categorizado) no texto, o objeto é recategorizado por meio da estratégia de referenciação. Esse processo de construção e reconstrução de objetos de discurso é realizado por sujeitos em interação, o que significa dizer que carrega, dentre outros aspectos, os interesses e os pontos de vista dos interlocutores envolvidos no discurso.

Os referentes de que falamos não espelham diretamente o mundo real, não são simples rótulos para designar as coisas do mundo. Eles são construídos e reconstruídos no interior do próprio discurso, de acordo com a nossa percepção de mundo, nossos "óculos sociais”, nossas crenças, atitudes e propósitos comunicativos (KOCH; ELIAS, 2006, p. 123, grifo das autoras).

Para Mondada e Dubois (2003), os objetos de discurso, sendo construídos e desenvolvidos discursivamente, não devem ser entendidos como se já estivessem prontos para ser utilizados e, além disso, como se fossem válidos para todos os sujeitos, pois eles não são estáticos e não seguem uma norma, mas são construídos conforme o contexto de interação. Essa forma de conceber a referenciação é assumida por Koch, que propõe a seguinte descrição: "os objetos-de-discurso são altamente dinâmicos, ou seja, uma vez introduzidos na memória discursiva, vão sendo constantemente transformados, reconstruídos, recategorizados no curso da progressão textual" (2004, p. 40). Esse 
processo dinâmico, segundo a autora, desenvolve-se como uma atividade discursiva realizada por sujeitos históricos e socialmente situados.

Essa construção e reconstrução de objetos de discurso, que se constitui como um processo dinâmico na progressão textual, ocorre quando um objeto é lançado no texto e utilizado novamente por meio da reconstrução. Mondada e Dubois explicam melhor esse processo dinâmico ao afirmarem que "as categorias e os objetos de discurso são marcados por uma instabilidade constitutiva, observável através de operações cognitivas, ancoradas nas práticas, nas atividades verbais ou não verbais, nas negociações dentro da interação" (2003, p. 17).

Nessa mesma perspectiva, Koch e Marcuschi (1998) compreendem que a referenciação não deve ser vista como maneira de "etiquetar" o mundo, mas como uma atividade que ocorre no instante da produção do discurso. Segundo os autores, "no contexto do discurso, todos os referentes são evolutivos, já que sempre haverá uma mudança, ou seja, os referentes modificam-se à medida que o discurso se desenrola" (KOCH; MARCUSCHI, 1998, p. 173).

Essa forma de interpretar a referenciação atrela-se à concepção teórica que considera a linguagem como um modo de ação social, conforme abordado no tópico anterior. As discussões sobre os processos de referenciação estão ligadas às ações desenvolvidas na língua, e estas são identificadas com base nas condições de inserção das informações no texto, sinalizando determinadas intenções. O produtor, ao inserir e retomar certos objetos de discurso, faz escolhas que não são gratuitas. Ao contrário, esperando alcançar seus objetivos, faz escolhas que estão permeadas de estratégias de convencimento, estabelecendo uma orientação argumentativa no texto. Nessa perspectiva, Koch afirma: "A referenciação constitui, assim, uma atividade discursiva. $\mathrm{O}$ sujeito, na interação, opera sobre o material linguístico que tem à sua disposição, operando escolhas significativas para representar estados de coisas, com vistas à concretização do seu projeto de dizer" (2004, p. 31).

Seguindo esse viés teórico, Marcuschi explica que "a referência deve ser tomada como ato criativo de designação" (2003, p. 43). Em outras palavras, ao utilizar estratégias de referenciação, o produtor não está isento de intenções, mas as utiliza porque quer reforçar certo argumento, quer mostrar algo para o outro. Assim, ao optar por um determinado objeto de discurso para designar um referente, o produtor posiciona-se, tendo em vista que a escolha da "existência de um objeto de discurso implica em observar o tipo de apreciação axiológica que sobre ele incide e qual a voz social o enuncia - afinal, estas são as condições para a constituição de discursos e de, é claro, objetos de discurso" (ALVES FILHO, 2010, p. 214).

Mais uma vez, a referenciação é afirmada como uma forma de referendar 
objetos de discurso, os quais carregam consigo características dos sujeitos históricos socialmente situados. Assim sendo, tomado sob o viés discursivo e, consequentemente, como produto da ação interativa entre os sujeitos envolvidos na constituição dos textos, o processo de referenciação constitui-se como uma atividade linguística que não se limita à decodificação textual, nem se reduz à localização de um termo no texto, mas se coloca como um recurso estratégico na construção do sentido textual.

Levando em consideração que o trabalho aqui proposto não permite trabalhar com todos os possíveis elementos referenciais, optamos por focalizar as retomadas não correferenciais - sem a manutenção do núcleo -, tendo em vista que elas são concebidas como uma forma de manifestação do produtor do texto $(\mathrm{KOCH}$, 2005). Isso porque utilizar uma anáfora não correferencial para recategorizar um referente implica sempre uma escolha lexical em detrimento de tantas outras possibilidades existentes na língua, e essa escolha pode revelar opiniões, intenções e atitudes do produtor do texto.

Dentre as retomadas sem a manutenção do núcleo, destacamos as pronominais; as expressões nominais referenciais, definidas ou indefinidas; as anáforas especificadoras, por meio da sequência hiperônimo/hipônimo; as paráfrases anafóricas, definicionais ou didáticas; as expressões sinônimas ou quase sinônimas; e, por fim, as anáforas rotuladoras (KOCH; ELIAS, 2006). A possibilidade de orientar os sentidos do texto por meio das escolhas linguísticas atualizadas no processo de referenciação - no nosso caso, por meio das anáforas não correferenciais - marca o estreito relacionamento que se estabelece entre as noções de referenciação e argumentação.

Ressaltamos que o uso das anáforas não correferenciais contribui para a organização textual, introduz informação nova a respeito do referente e constitui-se numa estratégia de orientação argumentativa, pois, ao reconstruir os objetos de discurso, os sujeitos os direcionam conforme seus objetivos, buscando persuadir por meio da linguagem.

\section{O gênero fábula e suas nuances}

Fábula é uma palavra de origem latina "usada para significar relato, conversação ou narração alegórica" (COELHO, 1984, p. 23) e provém do verbo fabulare (falar), uma das mais antigas formas de narrativa (tradição oral), construída em verso ou em prosa, que se utiliza do lúdico para transmitir uma lição de moral. Suas personagens são, geralmente, animais, que representam facetas do ser humano, como o egoísta, o ingênuo, o espertalhão, o vaidoso, o mentiroso etc. $\mathrm{O}$ gênero divide-se em duas partes: a história - o que aconteceu - e a sua moral - o significado da história (COELHO, 1984).

Segundo Fernandes, a "fábula é um texto narrativo que registra o modo de 
vida dos povos" (2001, p. 07). De acordo com a autora, há muitos anos, o homem sentiu necessidade de falar sobre as coisas da natureza, sobre a sociedade da época, sobre suas viagens, sua vida, seus desejos e, por isso, começou a contar histórias. Dentre essas histórias, estão as fábulas, que atribuem aos animais e às coisas características humanas e têm como intuito aconselhar a sociedade. "Revelando preocupação com as ações humanas, a fábula retrata valores gerais, como vícios, fraquezas, virtudes e desejos do homem, o que faz com que ela resista ao tempo e continue pertinente em qualquer época" (COELHO, 1984, p. 37).

Para Coelho (1984), a fábula é dotada de uma linguagem metafórica. Utilizando imagens, símbolos e alegorias, por exemplo, o gênero traduz valores com vistas a alcançar os leitores. Nesse sentido, o aluno, ao deparar-se com esse gênero, deve utilizar-se das estratégias de interpretação para conseguir desvendar as intenções do autor. É bastante comum as pessoas fazerem uso das fábulas como forma de ensinamento e formatação de condutas sociais em suas vidas diárias. Especialmente quando o desejo é socializar algum conhecimento ou fato, o uso de fábulas parece surtir um efeito mais contundente, de caráter excepcionalmente educativo e explicativo (CECCON, 2010).

O fascínio despertado pelas fábulas é notável. Dois movimentos estão presentes nesse gênero da esfera literária. De um lado, as fábulas trazem realidades distantes para mais perto daqueles que as ouvem, fazendo-os refletir melhor sobre o que se diz e sobre suas próprias vidas e seus comportamentos. De outro, propiciam às pessoas uma viagem repleta de descobertas e verdades aparentemente escamoteadas por palavras distantes dos seus universos, mas poderosas o suficiente para modificar visões de mundo há muito cristalizadas e repetidas de modo mecânico e, não raro, de maneira inconsequente (COELHO, 1984).

A fábula, gênero literário bastante conhecido e explorado, de modo especial, junto às crianças, em alguns casos pelas escolas e em outros pelos pais, normalmente são utilizadas para passar aos alunos ou aos filhos, respectivamente, valores morais e regras de convívio social necessários a todos os seres humanos, conforme analisam as autoras acima citadas. Curiosamente, no entanto, quando comparada com outras obras, a fábula não tem estado no centro dos principais debates ocorridos nos círculos linguísticos. Apesar disso, é significativo seu valor, assim como a riqueza de dados de linguagem apresentados nesse gênero, tanto no nível lexical e sintático quanto no nível semântico. No bojo de toda gama de contribuição proporcionada pelas fábulas, o uso de palavras, muitas vezes desconhecidas pelos leitores, e os empréstimos de sentidos construídos à luz de figuras de linguagem e estilo, nesse caso envolvendo interessantes aspectos 
semânticos, têm espaço bem marcado, imprimindo aos textos um caráter fantasioso, ilustrativo, lúdico e, ao mesmo tempo e de modo especial, educativo e formatador de caráter, o que muito contribui para o aprendizado das crianças.

De acordo com Coelho (1984), nas fábulas, no que diz respeito à dimensão sintática, as construções adotadas, porque exploram estruturas sentenciais mais elaboradas, acabam por produzir um tipo de tessitura que vai exigir do leitor um raciocínio muito mais trabalhado. As várias ligações, combinações e jogos de palavras que povoam esse tipo de escrita levam o leitor a um universo linguístico muitas vezes diferente daquele no qual estaria situado quando da leitura de outros tipos de textos. E são justamente esses movimentos que tornam as fábulas obras muito especiais e, por conseguinte, relevantes para os estudos da linguagem e de seus fenômenos tão intrigantes.

Considerando esses fatos, buscamos não apenas discutir as fábulas em relação ao papel que desempenham na formação dos alunos, mas também, e especialmente, refletir sobre como os alunos interpretam tal gênero, levando em consideração o uso das anáforas não correferenciais na construção do significado do texto. Nessa perspectiva, adotamos como corpus de análise respostas interpretativas produzidas a partir do estudo das fábulas de La Fontaine, "A raposa e as uvas" e "O lobo e o cordeiro".

\section{Análise e descrição dos dados coletados}

Como local para a realização do trabalho, selecionamos a Escola Estadual Horácio Ribeiro dos Reis, situada em Cascavel, PR. Atualmente, esse colégio possui aproximadamente 1.800 alunos, distribuídos nos períodos matutino, vespertino e noturno, nos ensinos fundamental e médio, regular e supletivo. Alguns alunos, inclusos nas classes regulares de ensino, têm necessidades especiais, os quais necessitam de acompanhamento paralelo especializado e contínuo.

Para a coleta de dados, preparamos 7 horas-aula com a turma escolhida. No total, 30 alunos participaram da pesquisa feita em campo. Dividimos o trabalho em duas etapas: tivemos 24 alunos participantes na primeira etapa e 19 na segunda, devido às questões climáticas do dia. Também é necessário destacar que, para realizarmos a coleta de dados na escola, encaminhamos o projeto de pesquisa para o Comitê de Ética da Universidade Estadual do Oeste do Paraná, o qual foi aprovado no dia $1 \square$ de dezembro de 2010 , conforme o documento n. 507/2010.

Salientamos que os alunos do $6^{\circ}$ ano "A" selecionados para compor a pesquisa foram participativos, estabelecendo uma relação professor/aluno interativa, o que contribuiu para o bom funcionamento das aulas. Mesmo assim, frisamos que os alunos tiveram dificuldade em trabalhar com o gênero fábula, que, apesar de ser 
bastante abordado na série em questão, ainda carece de reflexão.

Para alcançar os objetivos estipulados, necessitamos dividir as análises em duas etapas, uma referente à primeira coleta de dados (etapa de leitura) e a outra, à segunda coleta (etapa de ensino de leitura). Na primeira fase, verificamos o modo como os alunos interpretaram a fábula "A raposa e as uvas" de La Fontaine, sem ter sido antes trabalhada a estratégia linguística proposta. $\mathrm{Na}$ segunda fase, observamos como interpretaram a fábula "O lobo e o cordeiro", também de La Fontaine, após estudo das anáforas não correferenciais. Buscamos constatar se, após a estratégia explorada, os alunos utilizaram tais anáforas em suas respostas interpretativas, demonstrando compreensão da fábula em questão.

Nessa perspectiva, depois da coleta do corpus em campo, o próximo passo foi transcrever as respostas interpretativas dos alunos para procedermos às análises. Salientamos que as respostas interpretativas foram transcritas da forma como foram produzidas, ou seja, mantendo-se casuais problemas formais relacionados a acentuação, ortografia, normas gramaticais em geral, questões que não são tratadas neste trabalho.

Assim, ilustramos, sucintamente, por meio de quadros, as respostas interpretativas dos alunos relativas à primeira etapa. Logo após, seguimos para a segunda etapa, com o mesmo esquema. A fábula e suas respectivas atividades estão transcritas no final do trabalho. Salientamos que, devido às normas do relato, não apresentamos aqui todas as respostas dos alunos. Trazemos, na sequência, alguns exemplos, de modo a demonstrar os resultados obtidos.

Observamos, na primeira etapa, que a maioria das respostas dos alunos não ultrapassou o processo de decodificação. Ou seja, de maneira geral, os estudantes não evidenciaram uma interpretação bem-sucedida da fábula em questão, pois as repetidas cópias do enredo revelam que não conseguiram compreender a intenção principal dos autores. Vejamos o Quadro 1:

Quadro 1 - Respostas limitadas ao processo de decodificação

\begin{tabular}{|l|l|}
\hline R1 & $\begin{array}{l}\text { "Eu entendi que avia uma Raposa morta de fome e ela acho muitas uvas, e ela } \\
\text { estava louca para comer as uvas só que por mais que ela tentasse alcançar as uvas } \\
\text { ela não conseguia por que as uvas estavam muito autas. Então a Raposa foi em } \\
\text { bora dizendo que por ela podiam pegar todas as uvas e levar em borá que ela não } \\
\text { se emportar e as uvas estavas verdes e azedas e que ela não comeria essas uvas." }\end{array}$ \\
\hline
\end{tabular}

No exemplo citado, que representa as respostas obtidas na primeira etapa, vemos que estas nada acrescentam ao que o autor das fábulas apresenta de forma explícita. Ou seja, não expõem o ponto de vista do produtor do texto sobre o assunto abordado. Também é interessante salientar que em nenhuma dessas respostas o olhar do aluno se volta para a moral da fábula. 
Agora, vejamos o Quadro 2, que representa a segunda etapa da coleta de dados, após ser trabalhada a estratégia proposta:

Quadro 2 - Retomadas não correferenciais do referente "o cordeiro" por meio de expressão nominal referencial

\begin{tabular}{|c|c|c|l|}
\hline R2 & $\begin{array}{c}\text { Resposta } \\
\text { do aluno }\end{array}$ & o esperto & $\begin{array}{l}\text { "Que os tempos mudaram o cordeiro é o esperto e o } \\
\text { lo pode até ser forte mais é um bobão." }\end{array}$ \\
\hline R7 & $\begin{array}{l}\text { Resposta } \\
\text { do aluno }\end{array}$ & o carneirinho & $\begin{array}{l}\text { "Que o carneirinho estava bebendo água aí veio a } \\
\text { sombra do lobo, um bichu orrivel que come carne } \\
\text { e que tem os dente enorme, ele queria come o } \\
\text { cordeirinho, mais o carneirinho estava tentando } \\
\text { ganhar tempo até o casador chegar o caçador matou } \\
\text { o lobo." }\end{array}$ \\
\hline R17 & $\begin{array}{l}\text { Resposta } \\
\text { do aluno }\end{array}$ & O sabidinho & $\begin{array}{l}\text { "Eu entendi que o lobo veio se axano e se deu mau. } \\
\text { O sabidinho enrolo ele respondeno suas piadia até } \\
\text { chega o cassador." }\end{array}$ \\
\hline R18 & $\begin{array}{l}\text { Resposta } \\
\text { do aluno }\end{array}$ & o canerinho & $\begin{array}{l}\text { "Nessa o lobo vem dano uma de esperto mais o } \\
\text { canerinho começo comversar, começo responde as } \\
\text { tres pergunta do lobo até chega o cassador, daí ele } \\
\text { matou o lobo mal e levo pra casa pra come." }\end{array}$ \\
\hline
\end{tabular}

Nesse quadro, verificamos, em R7 e em $\mathrm{R} 18$, que os alunos retomaram o referente $o$ cordeiro por meio de expressões anafóricas sinônimas, o carneirinho/o carnerinho. Já nas respostas R2 e R17, observamos que o aluno recategorizou tal referente com as expressões o esperto e o sabidinho, que, além de descreverem, expressam sua avaliação sobre a personagem. Nesse sentido, tais formas referenciais demonstram, por parte do aluno, compreensão textual, pois ele não se limitou à mera repetição; ao contrário, realizou "uma escolha dentre as propriedades ou qualidades capazes de caracterizar o referente" (KOCH, 2004, p. 251).

Observamos, na sequência, o Quadro 3, que também faz parte da segunda coleta de dados:

Quadro 3 - Retomadas não correferenciais do referente "o lobo" por meio de construção de paráfrase anafórica didática

\begin{tabular}{|c|c|c|}
\hline $\begin{array}{c}\text { Resposta } \\
\text { do aluno }\end{array}$ & $\begin{array}{c}\text { um bichu orrivel que } \\
\text { come carne e que tem } \\
\text { os dente enorme }\end{array}$ & $\begin{array}{l}\text { "Que o carneirinho estava bebendo água aí veio a } \\
\text { sombra do lobo, um bichu orrivel que come carne e que } \\
\text { tem os dente enorme, ele queria come o cordeirinho, } \\
\text { mais o carneirinho estava tentando ganhar tempo até o } \\
\text { casador chegar o caçador matou o lobo." }\end{array}$ \\
\hline
\end{tabular}


Nesse quadro, o aluno realiza a construção de uma paráfrase anafórica didática. A expressão anafórica um bichu orrivel que come carne e que tem os dente enorme define o termo lobo, anteriormente introduzido no texto. $\mathrm{O}$ aluno sentiu necessidade de descrever tal objeto de discurso, comprovando, então, seu conhecimento sobre tal animal, bem como demonstrando o contato com outras histórias.

As respostas interpretativas dos alunos coletadas na primeira e na segunda fase foram analisadas e confrontadas. Os resultados obtidos mostram que, mesmo pautados em trabalho realizado em um curto período, após a estratégia proposta (segunda coleta), ao produzirem sua resposta interpretativa com base na fábula apresentada, os alunos realizaram suas estratégias de reconstrução do referente. Ao selecionar determinado item lexical no momento da reconstrução do objeto de discurso, os alunos, de forma geral, demonstraram seu modo de ver o objeto em questão, caracterizando-o conforme seu ponto de vista, o que evidencia compreensão da fábula.

Com essa segunda coleta de dados, verificamos que, após mostrarmos que, cada vez que 0 autor retoma determinado referente por meio de uma anáfora não correferencial, uma intenção pode ser recuperada, os alunos olharam mais para as relações entre as palavras, buscando analisar tais expressões. Isso fica claro quando vemos, nas respostas, que os alunos registraram seu olhar acerca do objeto de discurso em questão, recategorizando-o conforme seu conhecimento de mundo, suas leituras já realizadas. Assim, para mostrar seu ponto de vista, houve instantes em que criaram recategorizações por meio de expressões usadas no dia a dia, como também expressões vistas em outras histórias.

Diante do exposto, depois da estratégia proposta, constatamos mais ocasiões de compreensão acerca da fábula do que simplesmente decodificação. Notamos que os alunos perceberam a dinamicidade da linguagem, tendo em vista as diferentes versões interpretadas. Além disso, percebemos respostas mais elaboradas e compreensíveis se comparadas às da etapa anterior, o que indica ser essa mais uma função das anáforas não correferenciais.

Observamos que as anáforas não correferenciais analisadas, dadas nas respostas interpretativas, foram motivadas pela proposta estabelecida. Sendo assim, vemos que elas asseguram a unidade temática, a coesão e a coerência textual, inclusive orientando o texto argumentativamente, pois, ao selecionar determinado léxico, em detrimento de outros, o aluno demonstra seu posicionamento. Em outras palavras, ao usar o recurso em tela em suas respostas, o aluno deixa transparecer suas escolhas com a finalidade de destacar traços ou características do referente e, assim, de avaliá-lo segundo suas crenças, seu ponto de vista. Desse modo, constatamos 
que as anáforas não correferenciais auxiliaram na construção dos sentidos do texto (KOCH, 2004).

\section{Considerações finais}

Verificamos, com base nas reflexões aqui instauradas, que interpretar um texto não é algo simples; ao contrário, é uma tarefa árdua, que exige atenção do leitor, pois "é no interior do ato de leitura, enfrentando os desafios colocados pelo texto, que se aprende a usar as estratégias de leitura como ferramenta para desenvolver técnicas próprias e eficientes para o processo interpretativo" (KLEIMAN, 2009, p. 56).

Além disso, podemos dizer que a reconstrução de objetos de discurso tem por função não só manter o referente em foco como também estabelecer um processo de construção do significado. Nesse sentido, nós professores de língua portuguesa devemos ensinar nossos alunos a ler os implícitos do texto, a valorizar as relações lexicais estabelecidas entre as palavras e a estabelecer um trabalho constante com a interpretação textual embasada nos elementos linguísticos.

Diante do trabalho realizado, confirmamos que a referenciação não só estabelece a coesão textual como, nesse mesmo processo, também conduz o sentido que o produtor quer dar ao texto. Assim sendo, as anáforas não correferenciais devem ser observadas pelo professor de língua portuguesa e mostradas para o aluno/leitor, que pode utilizá-las em suas produções textuais quando tiver a intenção de evidenciar seu ponto de vista, seus valores e suas crenças acerca do assunto sobre o qual está redigindo, o que faz por meio de escolhas lexicais. Nós professores devemos ensinar nossos alunos a ler os implícitos do texto, a valorizar as relações lexicais formadas entre as palavras e, principalmente, a considerar a interface linguística e literária, o que torna mais rico e produtivo o ensino-aprendizagem.

\section{The reference element in the construction of meanings of gender fables}

\section{Abstract}

Given the difficulty that students feel when interpreting a text, this article aims to reflect on the interpretive process in the teaching of the Portuguese language. More specifically, we discussed the value of linguistic elements that play at the moment of textual interpretation of the fable genre. Among the several existing language resources, this paper discusses elements that collaborate in the construction of meanings and the fabric of the text, focusing, then the referencing process. In order to promote, considering the limits and possibilities of this investigation, a more precise understanding of the corpus, possible references among elements in the Portuguese language, we chose to focus on the coframe not resume in order to be conceived as a form of manifestation of the producer text (KOCK, 2005). The assumption 
is that the approach of this language resource in the teaching of the Portuguese language can help students in textual interpretation in view of its role in the process of extracting relevant information from the text. For the purpose of probing, we take as corpus analysis answers interpretive produced from the fable "The Wolf and the Lamb" of La Fontaine, by students of the 6th year in a public school of Rattlesnake-PR found that, when using such anaphora in their answers, students left their choices transpire in order to highlight traits or characteristics of the referent, and thus evaluate it according to their beliefs and views. In this direction, we found that students performed strategies (re)construction of the referent, demonstrating understanding of the texts read.

Keywords: Anaphora not coreferential. Gender fable. Textual interpretation. Interconnection linguistic and literary.

\section{Referências}

ALVES FILHO, Francisco. Sua casinha é meu palácio: por uma concepção dialógica de referenciação. Linguagem em (dis)curso, Palhoça, SC, v. 10, n. 1, p. 207-226, jan./abr. 2010. Disponível em: <http://www3.unisul.br/ paginas/ ensino/pos/linguagem/1001/100109. pdf $>$. Acesso em: 14 jun. 2011.

CECCON, Ruth Barreiros. Fábulas: estratégias para leituras. In: SEMINÁRIO NACIONAL EM ESTUDOS DA LINGUAGEM: DIVERSIDADE, ENSINO E LINGUAGEM, 2, 2010, Cascavel. Anais... Cascavel: Edunioeste, 2010. CD-ROM.

COELHO, Nelly Novaes. A literatura infantil: história, teoria, análise. 3. ed. São Paulo: Quíron, 1984.
COSTA-HÜBES, Terezinha da Conceição. Produção escrita de textos: atividades didáticas de interação social. Ponta Grossa: UEPG/ Cefortec, 2005.

COSTA VAL, Maria da Graça. Redação e textualidade. 2. ed. São Paulo: Martins Fontes, 1999.

FERNANDES, Mônica Teresinha Ottoboni Sucar. Trabalhando com os gêneros do discurso: narrar: fábula. São Paulo: FTD, 2001.

KLEIMAN, Ângela Bustus. Texto e leitor: aspectos cognitivos da leitura. São Paulo: Pontes, 2009.

. Oficina de leitura: teoria e prática. 10. ed. Campinas: Pontes, 2004.

KOCH, Ingedore Grunfeld Villaça. Argumentação e linguagem. São Paulo: Cortez, 2002.

. Linguagem e cognição: a construção e reconstrução de objetos-de-discurso. Veredas - Revista de Estudos Linguísticos, Juiz de Fora, v. 6, n. 1, p. 29-42, 2004.

. Referenciação e orientação argumentativa. In: KOCH, Ingedore Villaça; MORATO, Edwiges Maria; BENTES, Anna Christina (Orgs.). Referenciação e discurso. São Paulo: Contexto, 2005, p. 33-45.

O texto e a construção dos sentidos.

São Paulo: Contexto, 2008.

$\mathrm{KOCH}$, Ingedore Grunfeld Villaça; ELIAS, Vanda Maria. Ler e compreender: os sentidos do texto. São Paulo: Contexto, 2006.

KOCH, Ingedore Grunfeld Villaça; MARCUSCHI, Luiz Antônio. Processo de referenciação na produção discursa. DELTA - Revista de Documentação de Estudos em Linguística Teórica e Aplicada, São Paulo, v. 14, n. especial, p. 169-190, 1998.

LA FONTAINE, Jean de. A raposa e as uvas. Recanto das Letras. Disponível em: $<$ http://www.recantodasletras.com.br/biografias/1555766>. Acesso em: 20 out. 2011.

. Fábulas de La Fontaine. Belo Horizonte. Editora Itatiaia, 1992. 
MACHADO, Elisabeth Márcia Ribeiro. Lendo e compreendendo: uma experiência com $5^{\mathrm{a}}$ série. 2002. Dissertação (Mestrado em Linguística) - Instituto de Estudos da Linguagem, Universidade Estadual de Campinas, Campinas, 2002.

MARCUSCHI, Luiz Antônio. Gêneros textuais: definição e funcionalidade. In: DIONÍSIO, Ângela Paiva; MACHADO, Anna Rachel; BEZERRA, Maria Auxiliadora (Orgs.). Gêneros textuais \& ensino. 2. ed. Rio de Janeiro: Lucerna, 2003.

. Exercícios de compreensão ou copiação nos manuais de ensino de língua? Em Aberto, Brasília, ano 16, n. 69, p. 64-82, jan./mar.1996.

MONDADA, Lorenza; DUBOIS, Danièle. Construção dos objetos de discurso e categorização: uma abordagem dos processos de referenciação. In: CAVALCANTE, Mônica; RODRIGUES, Bernardete; CIULLA, Alena (Orgs.). Referenciação. São Paulo: Contexto, 2003. (Coleção "Clássicos da Linguística”).

TRAVAGLIA, Luiz Carlos. Gramática e interação: uma proposta para o ensino de gramática no $1^{\circ}$ e $2^{\circ}$ graus. 5. ed. São Paulo: Cortez, 2000.

\section{Anexo}

\section{A raposa e as uvas}

Morta de fome, uma raposa foi até um vinhedo sabendo que ia encontrar muita uva. A safra tinha sido excelente. Ao ver a parreira carregada de cachos enormes, a raposa lambeu os beiços. Só que sua alegria durou pouco: por mais que tentasse, não conseguia alcançar as uvas. Por fim, cansada de tantos esforços inúteis, resolveu ir embora, dizendo:

- Por mim, quem quiser essas uvas pode levar. Estão verdes, estão azedas, não me servem. Se alguém me desse essas uvas eu não comeria.

Fábula de LA FONTAINE (Século XVII)

\section{Atividade}

1) Diante da fábula "A raposa e as uvas", de La Fontaine, responda:

a) $\mathrm{O}$ que você entendeu da fábula "A raposa e as uvas" de La Fontaine?

\section{O lobo e o cordeiro}

$\mathrm{Na}$ água limpa de um regato, matava a sede um cordeiro, quando, saindo do mato, veio um lobo carniceiro.

Tinha a barriga vazia, não comera o dia inteiro. - Como tu ousas sujar a água que estou bebendo? - rosnou o Lobo a antegozar o almoço. - Fica sabendo que caro vais me pagar! - Senhor - falou o Cordeiro encareço à Vossa Alteza que me desculpeis, mas acho que vos enganais: bebendo, quase dez braças abaixo de vós, nesta correnteza, não posso sujar-vos a água.

- Não importa. Guardo mágoa de ti, que ano passado, me destrataste, fingido!

- Mas eu nem tinha nascido.

- Pois então foi teu irmão.

- Não tenho irmão, Excelência.

- Chega de argumentação.

Estou perdendo a paciência!

- Não vos zangueis, desculpai!

- Não foi teu irmão? Foi o teu pai ou senão foi teu avô.

Disse o Lobo carniceiro.

$\mathrm{E}$ ao Cordeiro devorou.

Fábulas de LA FONTAINE (Século XVII) Atividade

1) Diante da fábula "O lobo e o cordeiro", de La Fontaine, responda:

a) $\mathrm{O}$ que você entendeu da fábula " $\mathrm{O}$ lobo e o cordeiro" de La Fontaine? 